\title{
Green Synthesis of Metallic Nanoparticles using Aqueous Plant Extract and their Antibacterial Activity
}

\author{
S. Saranya ${ }^{1 *}$, A. Eswari ${ }^{3}$, E. Gayathri ${ }^{3}$, S. Eswari ${ }^{2}$ and K. Vijayarani ${ }^{1}$ \\ ${ }^{1}$ Department of Animal Biotechnology, ${ }^{2}$ Department of Veterinary Physiology, \\ Madras Veterinary College, Tamil Nadu Veterinary and Animal Sciences University, \\ Chennai-600007, India \\ ${ }^{3}$ Department of Biotechnology, St. Joseph's College of Engineering, Chennai-600119, India \\ *Corresponding author
}

\section{A B S T R A C T}

Plant extracts from Musa ornate and Zea mays were used for the green synthesis of Copper $(\mathrm{Cu})$ and $\mathrm{Zinc}$ oxide $(\mathrm{ZnO})$ nanoparticles (NPs) from copper chloride and zinc sulphate solution respectively. Green synthesized metallic nanoparticles were characterized by UV-

\section{Keywords}

Copper, Zinc oxide, Musa ornate, Zea mays, Metallic nanoparticles, Antibacterial activity, Well diffusion method

Article Info

Accepted:

23 May 2017

Available Online:

10 June 2017 visible spectrophotometer, X-ray diffractometer (XRD), Fourier Transform Infra-Red spectrophotometer (FTIR), Scanning Electron Microscope (SEM), Transmission Electron Microscope (TEM), Atomic Force Microscope (AFM) and Zeta potential particle size analyser. Optimum parameters such as precursor salt solution concentration, $\mathrm{pH}$, ratio between reducing agent and precursor salt solution and reaction time, the formation and stability of the reduced metal nanoparticles in the colloidal solution were monitored by UV-visible spectrophotometer analysis. The mean particle diameter of nanoparticles was calculated from the XRD pattern according to the line width of the plane, refraction peak using the Scherrer's equation. FTIR results suggested that possible biomolecules for the reduction of metallic nanoparticles. SEM and TEM analysis showed the formation of well dispersed metallic nanoparticles and the synthesized metallic nanoparticles were in nano scale range. Antimicrobial activities of the metallic nanoparticles were performed by well diffusion method against Escherichia coli, Staphylococcus aureus, Streptococcus agalactiae and Salmonella enterica. Metallic $\mathrm{Cu}$ and $\mathrm{ZnO}$ NPs synthesized had antimicrobial activity against pathogenic bacteria and highest antimicrobial activity was found with Cu NPs synthesized using Musa ornate flower sheath against Staphylococcus agalactiae.

\section{Introduction}

Nanotechnology is an emerging area of science and synthesis of nanoparticles (NPs) has been the most important step in the field of nanotechnology (Albrecht et al., 2006). In the field of biology, nanoparticles have a variety of applications as vaccine/drug delivery systems, minerals, antibacterials, etc. A wide range of chemical and physical methods are being used for the synthesis of nanoparticles. Nevertheless, these methods have few constraints like the use of toxic solvents, high energy consumption, hazardous by products, etc. Biological synthesis of NPs has been found to be more advantageous than physio-chemical synthesis since biological synthesis is cost effective, environment 
friendly and could easily be scaled up for large scale synthesis and do not use high pressure, temperature and toxic chemicals (Forough and Farhad, 2010). Green synthesis of nanoparticles using plant extracts is gaining importance over chemical synthesis. Plant extracts with their role as surface stabilizing agents, act as bio template for the synthesis of nanoparticles. Better manipulation, crystal growth control and stabilization are other advantages of biological methods (Juhi et al., 2014) and green synthesis of nanoparticles plays a crucial role in diverse nano technological applications (Monalisa and Nayak, 2013).

Plant extracts are reported to have antioxidant and reducing properties which are responsible for the reduction of metal salt to their respective nanoparticles. Plant based method of nanoparticles synthesis eliminate the elaborate process of nanoparticles synthesis and are considered as beneficial because of the presence of wide range of bio molecules.

The bio molecules present in plants can act as capping and reducing agents and thus increase the rate of reduction and stabilization of nanoparticles. Biosynthesized metal nanoparticles are more stable in nature and their rate of synthesis is faster than other methods. The present study describes the green synthesis of metal nanoparticles and their characterization.

\section{Materials and Methods}

\section{Preparation of plant extract and precursor} salt solutions

Metal nanoparticles (Copper and Zinc oxide) were synthesized using aqueous extract of Musa ornate flower sheath and Zea mays cob sheath as a reducing agent. Copper Chloride $\left(\mathrm{CuCl}_{2}\right)$, and Zinc Sulphate $\left(\mathrm{ZnSO}_{4}\right)$ were used as precursor source for $\mathrm{Cu}$ and $\mathrm{ZnO}$ respectively. For the synthesis of copper and zinc oxide nanoparticles, various concentrations of $\mathrm{CuCl}_{2}$ and $\mathrm{ZnSO}_{4}(1,2,3,4$ and $5 \mathrm{mM}$ ) were prepared in distilled water. Sheaths were collected and thoroughly washed with sterile distilled water, dried and chopped into fine pieces. Plant extracts were prepared by using $20 \mathrm{~g}$ sheath per $100 \mathrm{~mL}$ of distilled water. The mixture was heated for 20 min at $60{ }^{\circ} \mathrm{C}$ and filtered through Whatman No. 1 paper. The filtrate was stored at $4{ }^{\circ} \mathrm{C}$ until further use.

\section{Synthesis of metal nanoparticles}

For the synthesis of metal nanoparticles, both the precursor salt solution and reducing agent were mixed in 1:1 ratio. For the reduction of $\mathrm{Cu}$ ions, Musa ornate flower sheath extract was mixed with aqueous $\mathrm{CuCl}_{2}$.

Similarly, for the reduction of Zn ions, Zea mays cob sheath extract was mixed with aqueous $\mathrm{ZnSO}_{4}$ solution. Then, the mixtures were constantly stirred at $70-80{ }^{\circ} \mathrm{C}$ overnight.

\section{Effect of concentration of precursor salt solution}

The effect of concentration of precursor salt solution was investigated for optimum synthesis of the two metallic nanoparticles by increasing the concentration of $\mathrm{CuCl}_{2}$ and $\mathrm{ZnSO}_{4}$ solutions from $1 \mathrm{mM}$ to $5 \mathrm{mM}$ with equal ratio of reducing agent. The absorbance (200 to $800 \mathrm{~nm}$ ) of the resulting solution was measured spectrophotometrically.

\section{Effect of pH}

$\mathrm{pH}$ of the reaction was optimized by increasing the $\mathrm{pH}$ ranges from 5 to 10 . The $\mathrm{pH}$ was adjusted using $0.1 \mathrm{~N} \mathrm{HCl}$ and $0.1 \mathrm{~N}$ $\mathrm{NaOH}$. After $\mathrm{pH}$ adjustment, absorbance (200 to $800 \mathrm{~nm}$ ) of the resulting solution was measured spectrophotometrically. 
Effect of ratio of sheath extract and precursor salt solution

The ratio of sheath extract and precursor salt solution was optimized by increasing the concentration of plant sheath extract $(10,20$, 30,40 and $50 \mathrm{ml}$ ) in $100 \mathrm{ml}$ of precursor salt solution (ratio - 1:9, 2:8, 3:7, 4:6 and 5:5). The absorbance (200 to $800 \mathrm{~nm}$ ) of the resulting solution was measured spectrophotometrically.

\section{Effect of time}

The reaction time was optimized for the reaction mixture by incubating at different time intervals such as $0,2,4,6,8$ and $24 \mathrm{hrs}$. The absorbance (200 to $800 \mathrm{~nm}$ ) of the resulting solution was measured spectrophotometrically.

\section{Characterization of metallic nanoparticles}

Synthesis of metallic nanoparticles was confirmed by measuring the absorbance in UV-Vis spectra at a range of $200-800 \mathrm{~nm}$. The powdered nanoparticles samples were analysed by XRD, FTIR, TEM, SEM, Zeta potential size and AFM. The X-ray diffraction (XRD) patterns were recorded using a Scintag 2000 PDS diffractometer with $\mathrm{Cu} \mathrm{K} \infty$ radiation with the $2 \theta$ range of $0-70^{\circ}$. XRD patterns were calculated using $X^{\prime}$ per Rota flex diffraction meter using $\mathrm{Cu} \mathrm{K}$ radiation and $\lambda=1.5406 \mathrm{~A}^{\circ}$. Crystallite size is calculated using Scherrer equation $\mathrm{CS}=\mathrm{K} \lambda / \beta$ $\cos \theta$ Where CS is the crystallite size Constant $[\mathrm{K}]=0.94 \beta$ is the full width at half maximum [FWHM] Full width at half maximum in radius $[\beta]=\mathrm{FWHM} \times \pi / 180 \lambda=$ $1.5406 \times 10-10, \operatorname{Cos} \theta=$ Bragg angle (Shobha et al., 2014).

FTIR measurements were carried out to identify the possible bio molecules responsible for the reduction of $\mathrm{Cu}, \mathrm{Zn}$ and capping of the bio-reduced copper and zinc oxide nanoparticles. FTIR was used to characterize the nanoparticles using the powdered nanoparticles samples by $\mathrm{KBr}$ pellet method. The absorbance maxima were scanned by FTIR at the wavelength of 400$4000 \mathrm{~cm}^{-1}$. The surface morphology and size of the particles were investigated using scanning electron microscopy with an acceleration voltage of $7 \mathrm{kV}$. In TEM analysis at $120 \mathrm{KV}$, samples were prepared on a conventional carbon coated copper grids by dropping a very small amount of the sample and drying in an incubator for $30 \mathrm{mins}$ to detect the size and shape of nanoparticles. For Zeta potential analysis, nanoparticles were dissolved in water and filtered through 0.22 $\mu \mathrm{m}$ pore sized filter. Then the samples were diluted for 4 to 5 times and then used for Zeta-Potential analysis. Powdered nanoparticles samples were characterised by AFM for its morphology and size. Images were taken using silicon cantilevers with contact mode.

\section{Antibacterial efficacy of metallic nanoparticles}

The metallic nanoparticles synthesized using sheath extracts of plant origin were tested for their antibacterial activity by well diffusion method against Streptococcus agalactiae, Staphylococcus aureus, Salmonella enterica and Esherichia coli. $24 \mathrm{hrs}$ fresh cultures were prepared and the standardized (McFarland No.0.5) inoculum was used for the antibacterial assay.

Each strain was uniformly swabbed on the individual plates. Wells of $5 \mathrm{~mm}$ were made on agar plates. Using micropipettes, $1 \mathrm{mg} / \mathrm{mL}$, $2 \mathrm{mg} / \mathrm{mL}, \quad 3 \mathrm{mg} / \mathrm{mL}$ and $4 \mathrm{mg} / \mathrm{mL}$ concentrations of nanoparticles solutions were poured into the wells on all plates. After incubation at $37{ }^{\circ} \mathrm{C}$ overnight, zones of inhibition were measured. 


\section{Results and Discussion}

Aqueous Copper and Zinc ions were reduced to $\mathrm{Cu}$ and $\mathrm{ZnO}$ NPs when added to flower sheath extract of Musa ornate and cob sheath extract of Zea mays. The appearance of light blue colour colloidal solution for $\mathrm{Cu}$ and dirty white colour precipitation for $\mathrm{Zn}$ (Figure 1) in the reaction mixture indicated the formation of the respective nanoparticles. The colour reaction arises from the excitation of surface Plasmon vibration in the metal nanoparticles (Shahverdi et al., 2007). Subhankari and Nayak (2013) have stated that the bio molecules present in the aqueous extract of plant origin not only reduced the metal ions but also stabilized the metal nanoparticles by preventing them from being oxidized after synthesis.

\section{UV-Visible spectrophotometric analysis}

Bioreduction of $\mathrm{Cu}$ and $\mathrm{ZnO}$ in aqueous solutions was monitored by periodic sampling of aliquots of the mixture and subsequently measuring the UV-Visible spectra. Synthesized nanoparticles were confirmed by UV-Visible spectrophotometer. Maximum absorbance peaks of Copper and Zinc oxide nanoparticles were observed at $300 \mathrm{~nm}$ and 275-375 nm respectively. The lambda maxima of synthesized nanoparticles were quite similar to those reported for $\mathrm{Cu}$ (Gopinath et al., 2014) and $\mathrm{ZnO}$ (Pattanayak and Nayak, 2013) respectively.

\section{Effect of precursor salt solution}

Results of our study on the effect of precursor salt solution, showed that $4 \mathrm{mM}$ and $5 \mathrm{mM}$ concentration of Copper chloride and Zinc sulphate resulted in maximum nano particle formation with the absorbance peak at $300 \mathrm{~nm}$ and $275-375 \mathrm{~nm}$ respectively (Figure $2 \mathrm{a}$ and b). The absorption spectra intensity of nanoparticles increased with increased concentration of precursor salt solutions. The results indicated a narrow size distribution of $\mathrm{Cu}$, and $\mathrm{ZnO}$ nanoparticles with Musa ornate and Zea mays sheath extracts as reducing agents.

\section{Effect of pH}

Reaction mixture $\mathrm{pH}$ is considered as an important parameter in nanoparticle synthesis. In our study, the solution was adjusted to different $\mathrm{pH}$ and the concentration of $\mathrm{CuCl}_{2}$ and $\mathrm{ZnSO}_{4}$ was kept at $4 \mathrm{mM}$ and $5 \mathrm{mM}$ in $1: 1$ ratio respectively. Reduction of $\mathrm{Cu}$ and $\mathrm{ZnO}$ NPs were observed based on the surface Plasmon resonance peak at $300 \mathrm{~nm}$. Maximum absorbance peak of $\mathrm{Cu}$ and $\mathrm{ZnO}$ nanoparticles was found at $\mathrm{pH} 9.0$ and 8.0 respectively (Figure 3a and b). In both cases, the spectra had single peaks indicating that the synthesized particles are specific. In general, alkaline and neutral $\mathrm{pH}$ was found to be optimum for the synthesis of metallic nanoparticles.

\section{Effect of ratio of precursor salt solution to reducing agent}

The ratio of precursor salt to the reducing agent in the formation of nanoparticles varies from plant to plant and it is reported that varying the amount of Aloe vera leaf extract in the reaction medium containing Chloroaurate ions, influenced the ratio of gold triangular plates to spherical nanoparticles (Chandran et al., 2006). In our study, different ratios of precursor salt solution to reducing agent were optimized and the maximum $\mathrm{Cu}$ and $\mathrm{ZnO}$ nanoparticle synthesis was achieved in 8:2 and 5:5 ratios respectively. This was further confirmed by the formation of highest peak in spectroscopy and colour formation. Thus these ratios were considered as optimum and the next parameter was performed based on this ratio and colour change (Figure 4a and b). The study also found that the Carbonyl 
compounds present in the extract assisted in shaping the particle growth.

\section{Effect of reaction time}

For the synthesis of metallic nanoparticles a reaction time of $0,1,2,3,4$ and 24 hrs were tested. Prolonged reaction time has been reported to increases the probability of collisions between particles, leading to aggregation. The UV-Vis graphs in Figure 5a and $b$ showed that there was no significant difference in the synthesis of both $\mathrm{Cu}$ and $\mathrm{ZnO}$ nanoparticles irrespective of the reaction time.

\section{X-Ray Diffraction (XRD) analysis}

The XRD patterns showed that the synthesized $\mathrm{Cu}$ nanoparticles were amorphous in nature and the $\mathrm{ZnO}$ nanoparticles in crystalline nature (Figure $6 a$ and b). The amorphous nature of the $\mathrm{Cu}$ NPs could be confirmed by the fact that the XRD patterns lacked distinct diffraction peaks and revealed broad humps at $2 \theta=30^{\circ}$ to $40^{\circ}$ which can be attributed to the organic materials in the matrix as has been observed earlier when
Copper nanoparticles were synthesised using aqueous sorghum bran extracts by Eric et al., 2011.

XRD patterns of $\mathrm{ZnO}$ nanoparticles synthesized using Zea mays leaf extract were found to be highly crystalline with diffraction angles of 33, 35, 38, 48, 57, 63 and 68 (Figure 6b) which correspond to the characteristic of $\mathrm{ZnO}$ nanoparticles. The average size of $\mathrm{ZnO}$ nanoparticles was found to be $38.62 \mathrm{~nm}$. These results were in good agreement with work reported by Sangeetha and Kumaraguru (2013). In their work, $\mathrm{ZnO}$ nanoparticles were synthesized using seaweeds. The average size of $\mathrm{ZnO}$ nanoparticles synthesized was $36 \mathrm{~nm}$.

\section{Fourier Transform Infra-Red Spectroscopy (FTIR) analysis}

The major absorption peaks in FTIR spectra of Musa ornate flower sheath extract were mainly located at 3254.05, 1635.17, 525.09, 474.54 and $419.00 \mathrm{~cm}^{-1}$ (Figure 7). Presence of spectra peak at $3254.05 \mathrm{~cm}^{-1}$ could be due to the $\mathrm{O}-\mathrm{H}$ stretching vibration of the phenol groups, which might be responsible for the formation and stabilization of nanoparticles.

Fig.1 Visual observation of synthesis of metallic nanoparticles (a) Cu NPs and (b) ZnO NPs
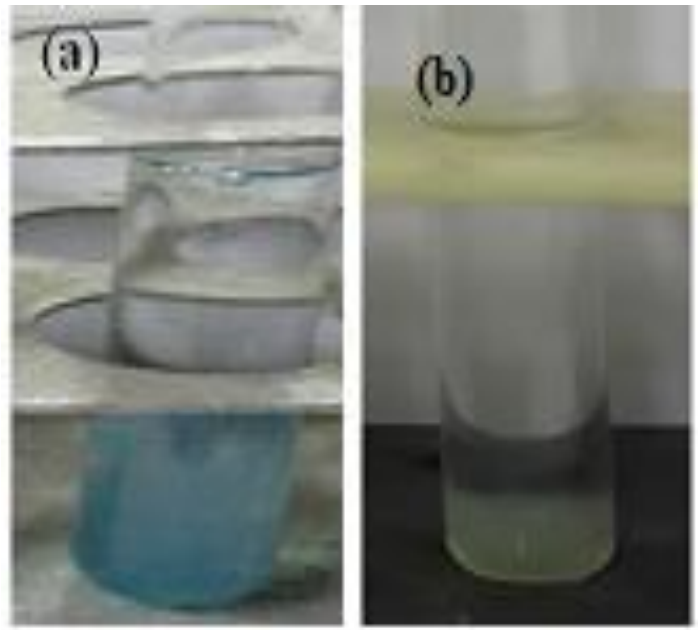
Fig.2 Effect of precursor salt concentration on metallic nanoparticles synthesis

$$
\text { (a) } \mathrm{CuCl}_{2} \text { (b) } \mathrm{ZnSO}_{4}
$$

(a)

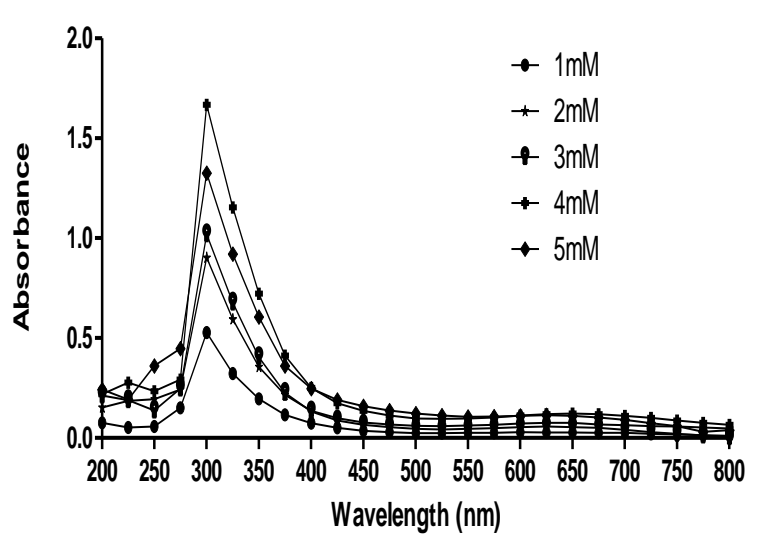

(b)

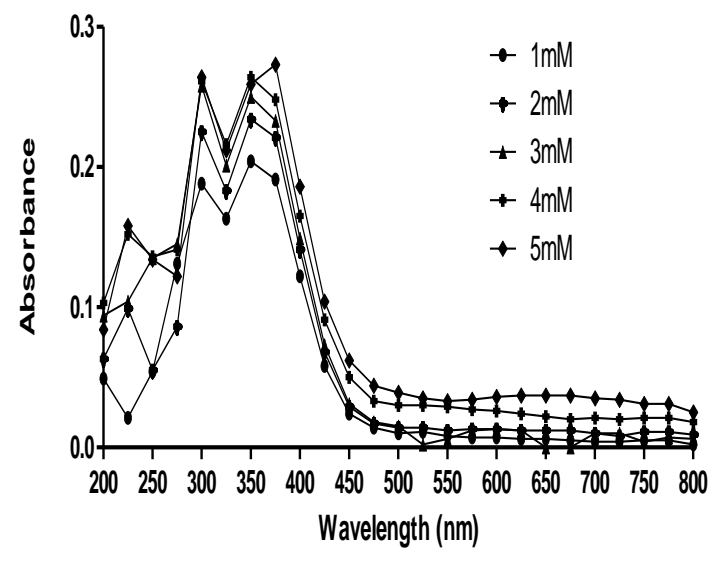

Fig.3 Effect of $\mathrm{pH}$ in the synthesis of metallic nanoparticles (a) $\mathrm{Cu}$ NPs and (b) ZnO NPs

(a)

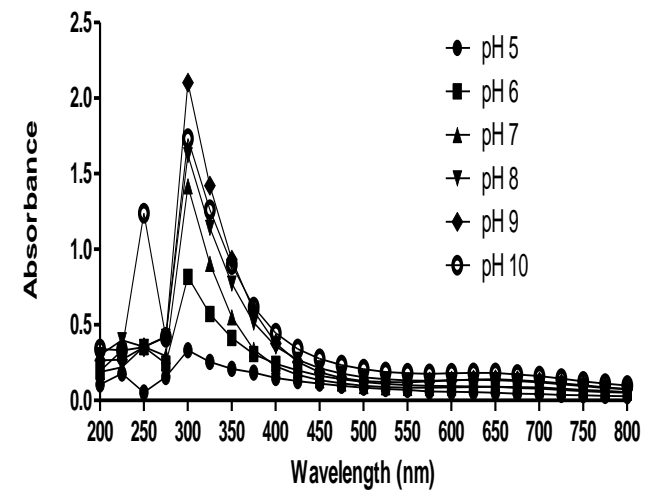

(b)

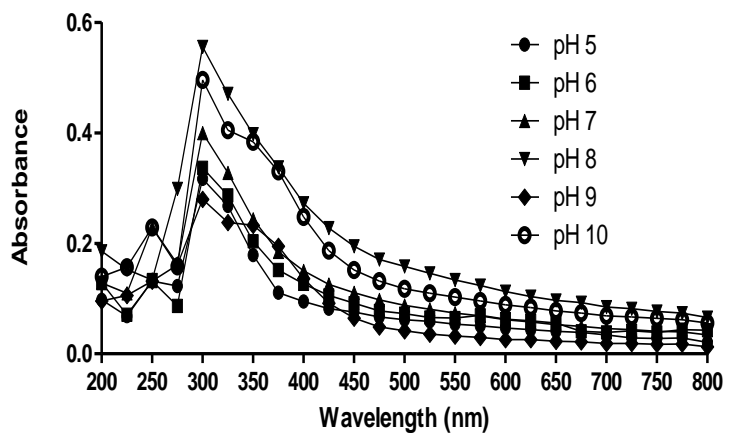

Fig.4 Effect of ratio between reducing agent and precursor salt solution for the synthesis of metallic nanoparticles (a) Cu NPs and (b) ZnO NPs
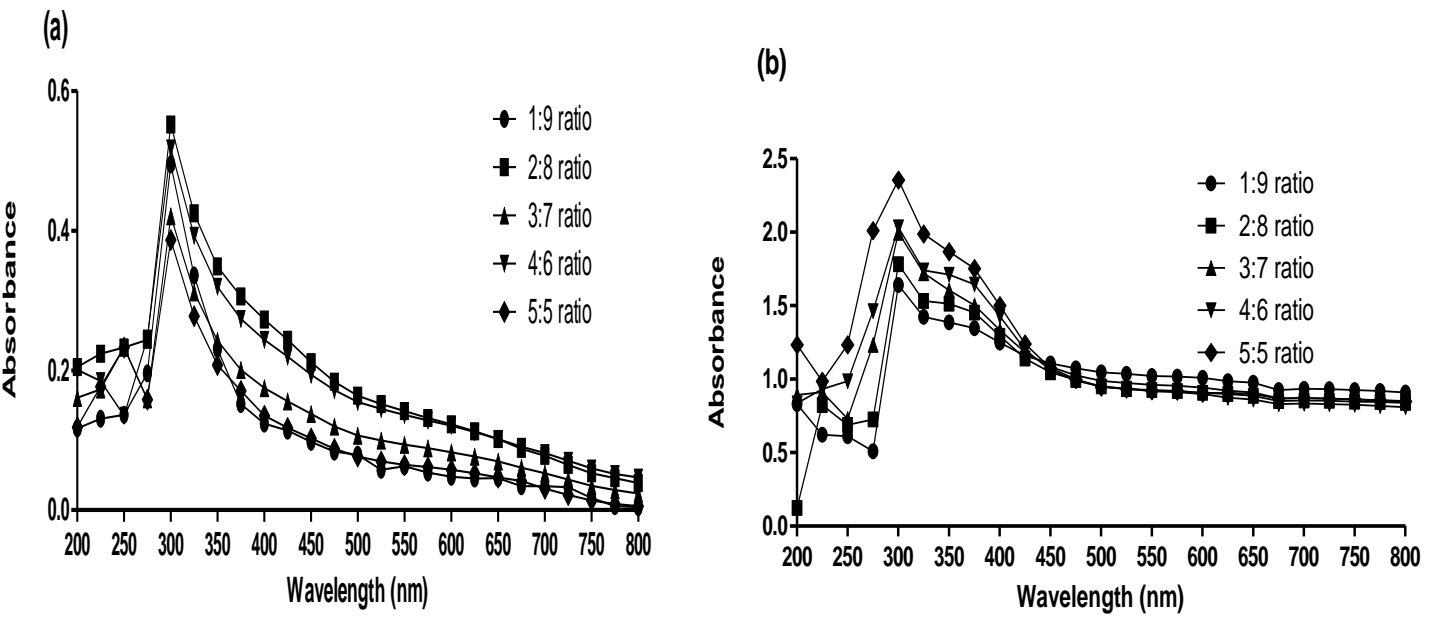
Fig.5 Effect of reaction time in the synthesis of (a) Cu NPs and (b) ZnO NPs

(a)

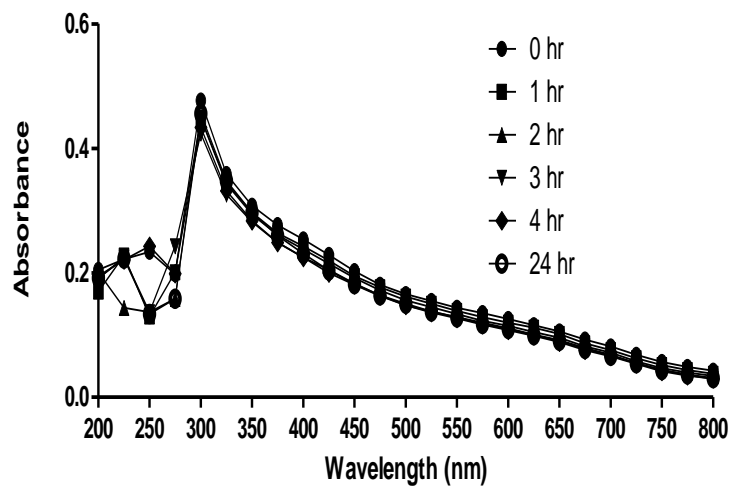

(b)

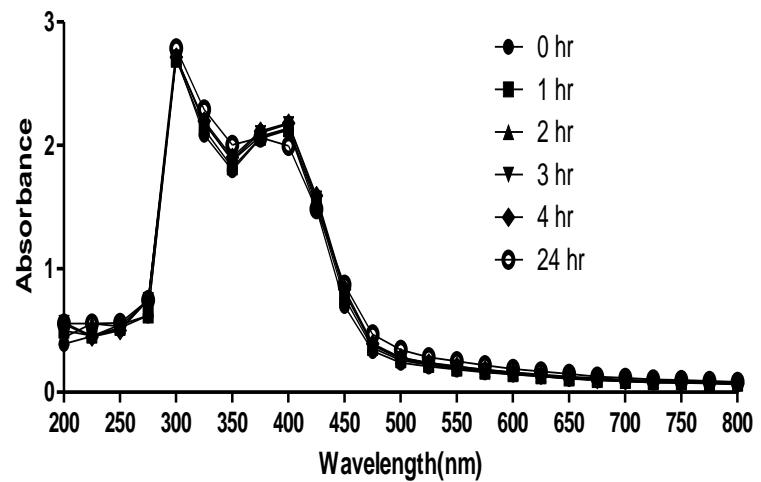

Fig.6 XRD analysis of (a) Cu NPs and (b) ZnO NPs
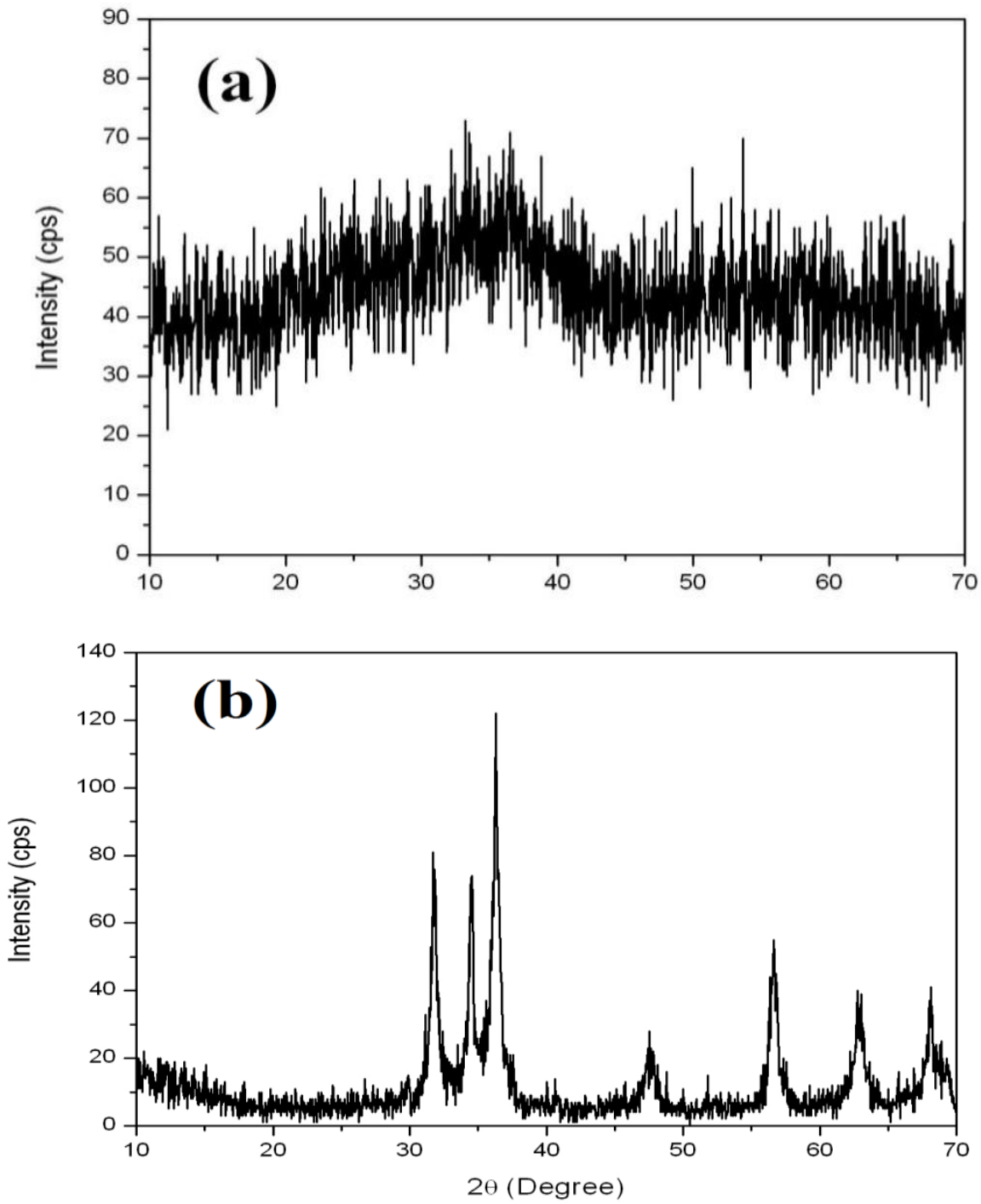

1840 
Int.J.Curr.Microbiol.App.Sci (2017) 6(6): 1834-1845

Fig.7 FTIR spectra of Musa orate leaf extract

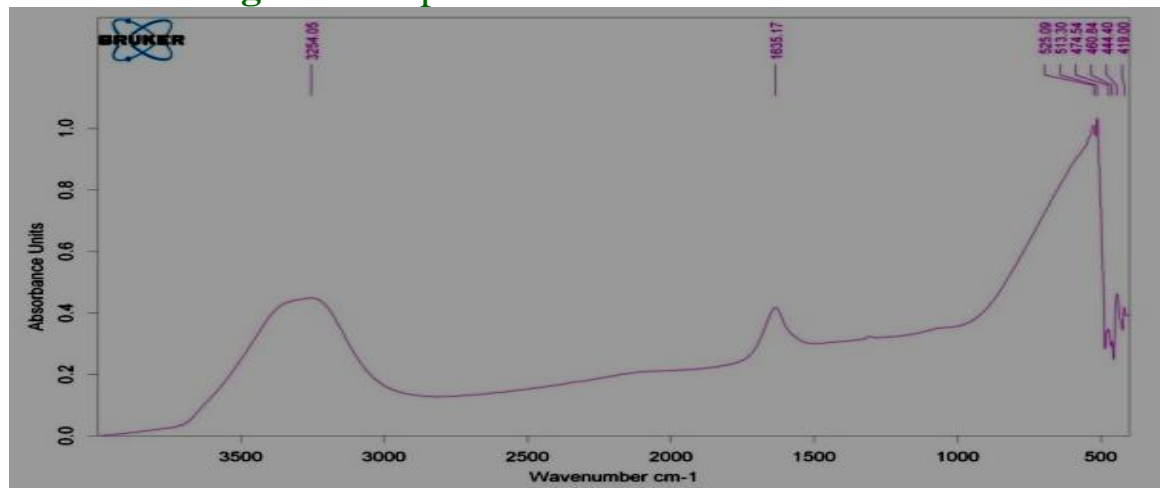

Fig.8 FTIR spectra of Cu NPs

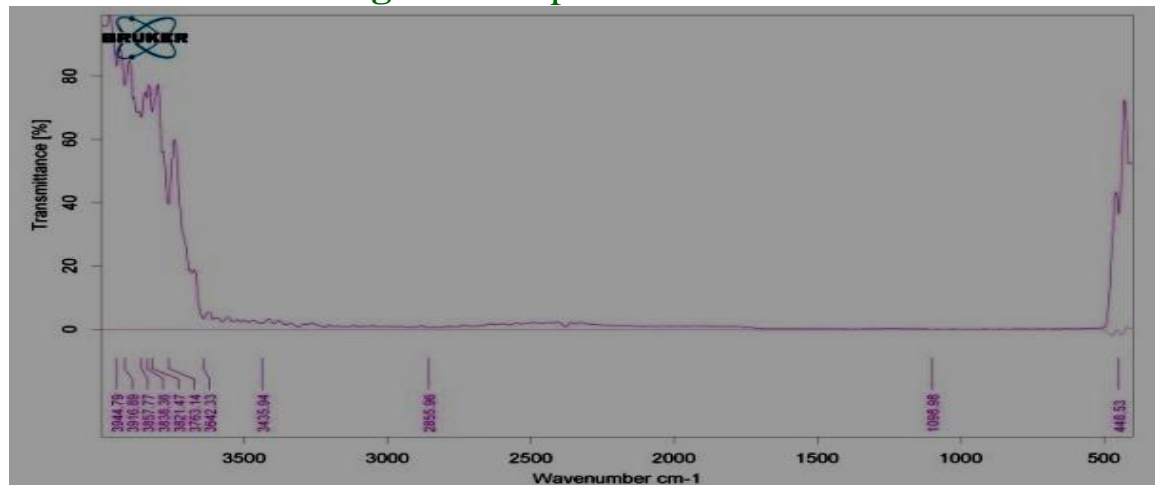

Fig.9 FTIR spectra of Zea mays leaf extract

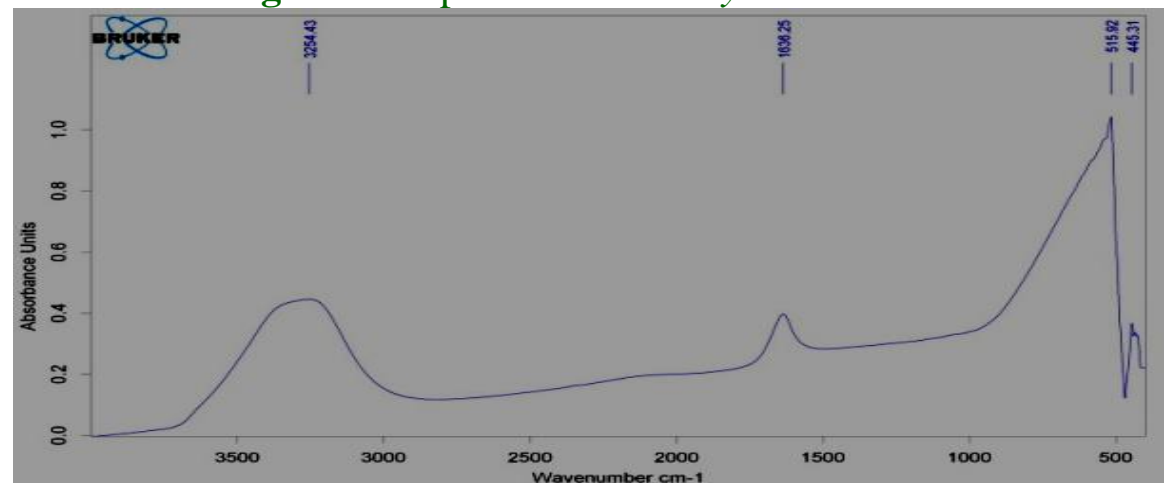

Fig.10 FTIR spectra of ZnO NPs

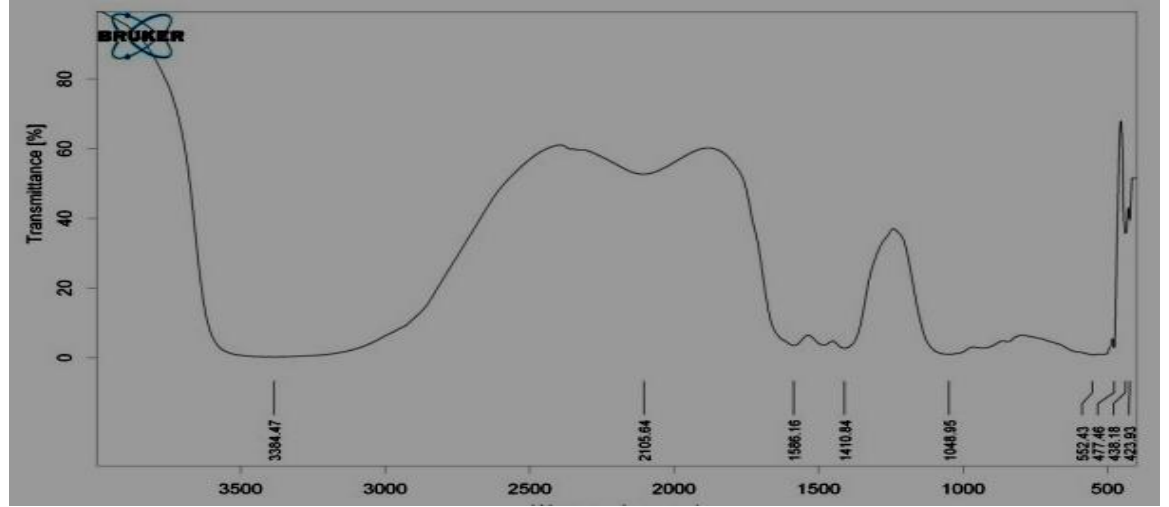


Fig.11 Scanning electron microscopic image of (a) $\mathrm{Cu}$ NPs and (b) ZnO NPs
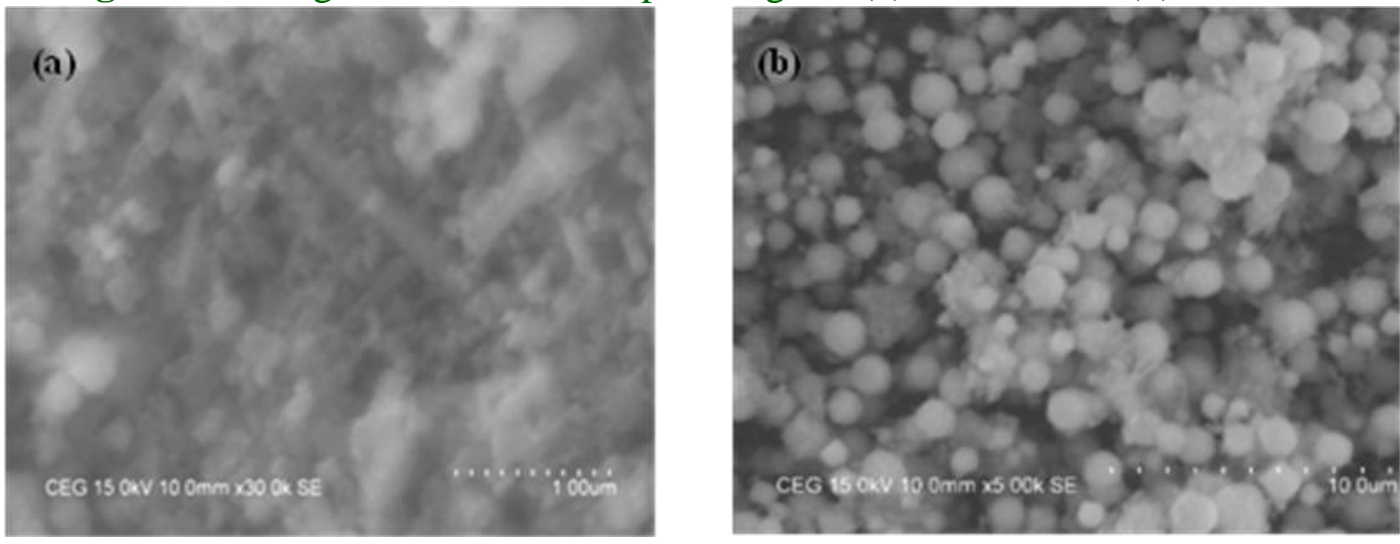

Fig.12 Transmission electron microscopic image of (a) Cu NPs and (b) ZnO NPs
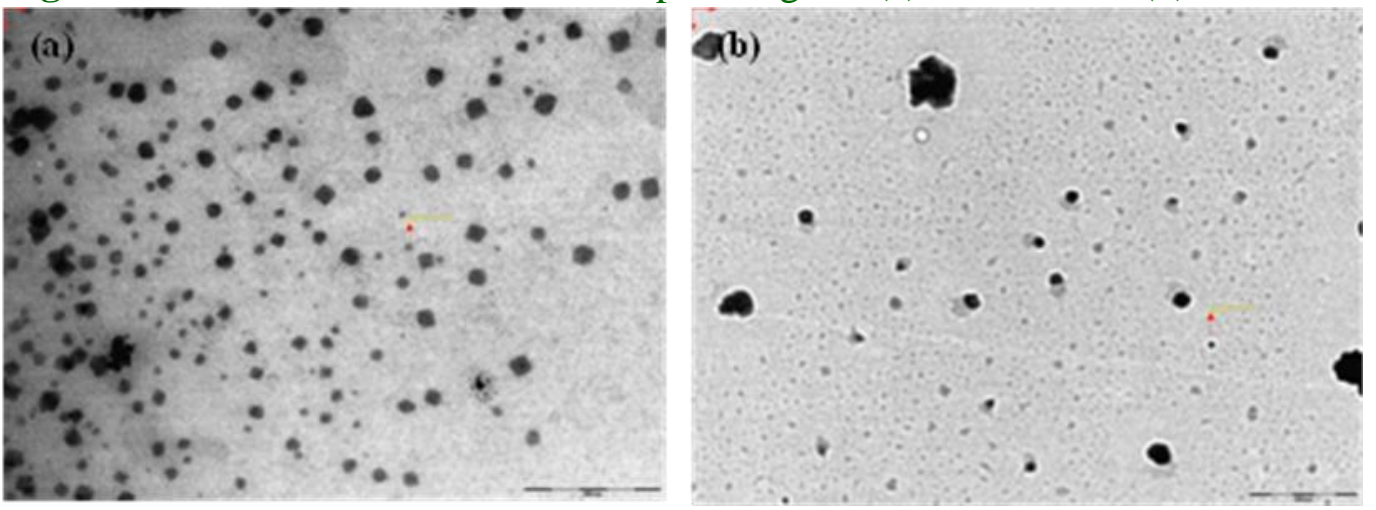

Fig.13 Percentage frequency of particle size distribution of (a) $\mathrm{Cu}$ NPs and (b) ZnO NPs
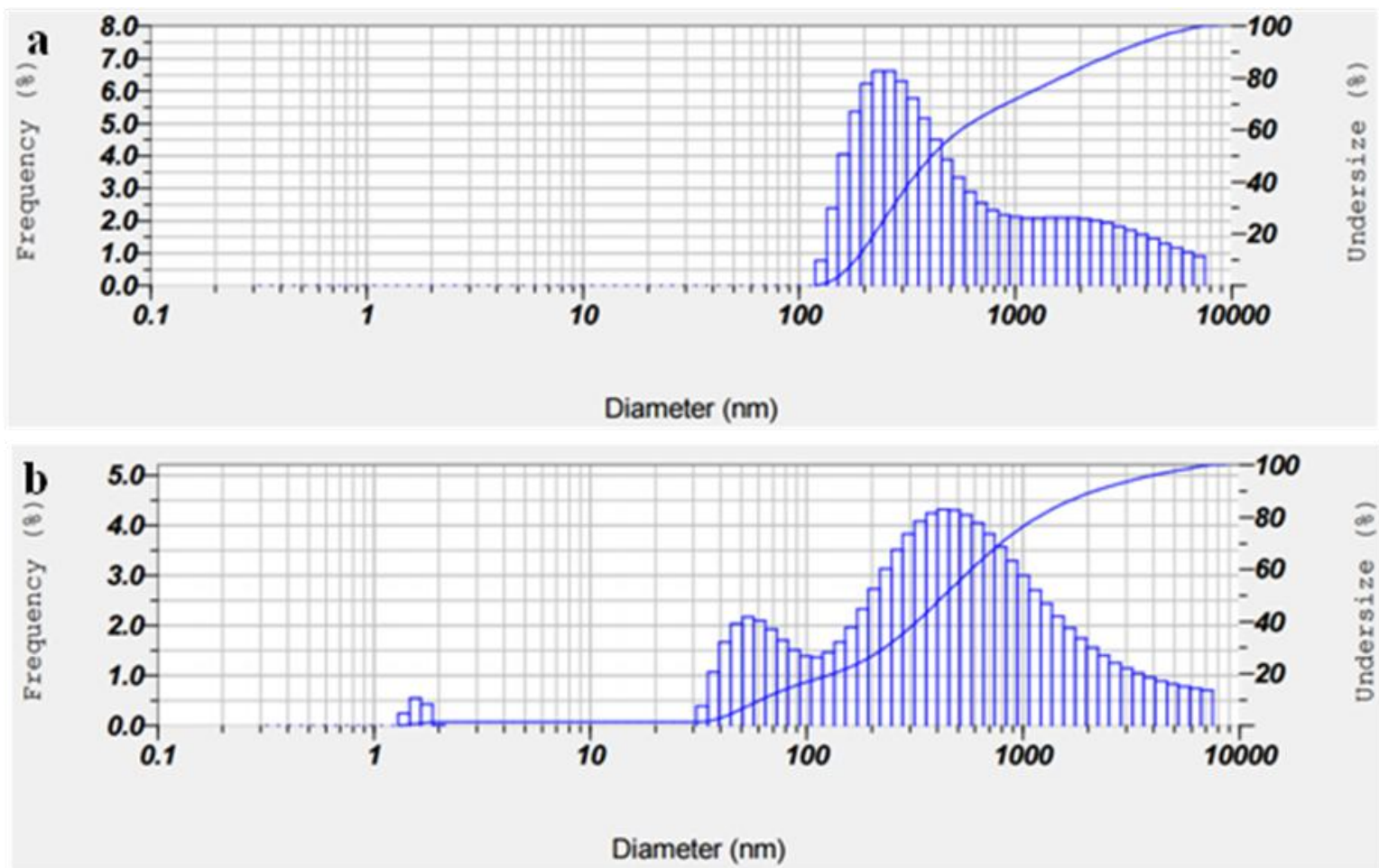
Fig.14 Atomic Force Microscopic image of (a) Cu NPs and (b) ZnO NPs
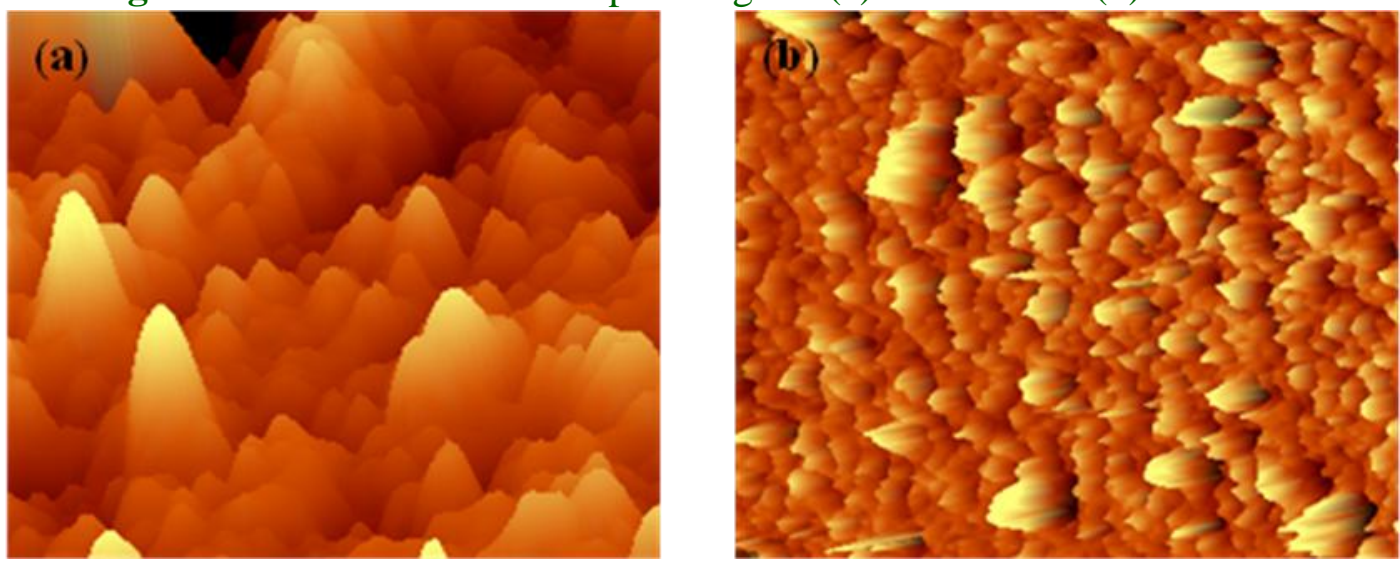

Fig.15 Antibacterial activity of metallic nanoparticles (a-d) Cu NPs and (e-h) ZnO NPs

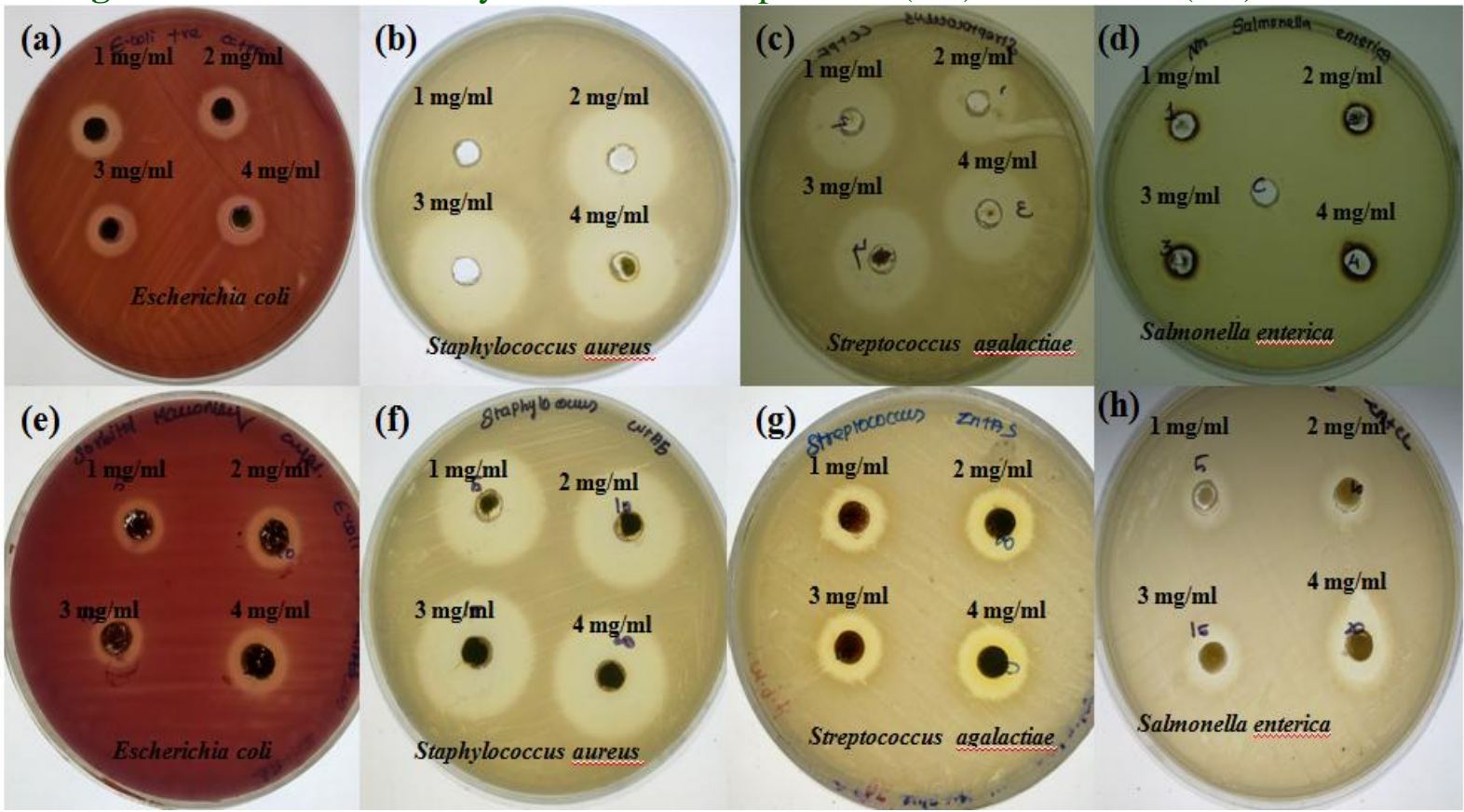

The major absorption peak in the FTIR spectra of synthesized $\mathrm{Cu}$ nanoparticles was mainly located at $3916.89,3821.47,3642.33$, 2855.96, 1095.95 and $446.53 \mathrm{~cm}^{-1}$ (Figure 8). The shift in peak from 3642.33 to 2855.96 $\mathrm{cm}^{-1}$ corresponds to $\mathrm{N}-\mathrm{H}$ bending which may be responsible for the reduction. The peak at $445.55 \mathrm{~cm}^{-1}$ indicated the vibration of copper nanoparticles.

Similarly in the FTIR spectra of Zea mays cob sheath extract, the peak at $1636.25 \mathrm{~cm}^{-1}$ corresponded to ester linkages or $\mathrm{C}-\mathrm{O}-\mathrm{H}$ stretch (Figure 9). The peak at $3254.43 \mathrm{~cm}^{-1}$ might have been due to the $\mathrm{O}-\mathrm{H}$ stretching vibration of phenolic compounds. The presence of $\mathrm{O}-\mathrm{H}$ groups of phenols might have been responsible for the formation and stabilization of the synthesized nanoparticles.

FTIR measurements were carried out to identify the possible biomolecules responsible for the reduction of $\mathrm{Zn}$ ions and capping of the reduced Zinc oxide nanoparticles. The band at $2105 \mathrm{~cm}^{-1}$ corresponds to the $\mathrm{N}-\mathrm{H} / \mathrm{C}$ $\mathrm{O}$ stretching vibration. Peaks at $438.18 \mathrm{~cm}^{-1}$ 
indicates the presence of $\mathrm{ZnO}$ nanoparticles (Figure 10) as has been observed earlier (Varghese and George, 2015).

\section{Electron Microscopic analysis}

Scanning electron microscopic (SEM) images of the $\mathrm{Cu}$ nanoparticles revealed that the preparation consisted of nanoparticles clusters with the size ranging from 150 to $200 \mathrm{~nm}$ (Figure 11a). However, further observations at higher magnifications revealed that these $\mathrm{Cu}$ nanoclusters have been assembled by smaller nanoparticles. SEM studies of Zn NPs revealed spherical and relatively spongy structures (Figure 11b). Transmission electron microscopic images of $\mathrm{Cu}$ and $\mathrm{ZnO}$ nanoparticles were spherical in shape with particle size in the nano range (approximately $48 \mathrm{~nm}$ ) (Figure 12a and b). $\mathrm{Cu}$ and $\mathrm{ZnO}$ nanoparticles synthesized in our study with Musa ornate flower sheath and Zea mays cob sheath were spherical in shape.

\section{Zeta potential particle size analysis}

Figure 13a and $\mathrm{b}$ presents a histogram of the particle size distribution of $\mathrm{Cu}$ and $\mathrm{ZnO}$ nanoparticles with the mean particle diameter (mean and standard deviation) of $391.6 \mathrm{~nm}$ and 239.7 for $\mathrm{Cu}$ NPs and 63.2 and 19.5 for $\mathrm{ZnO}$ NPs respectively. More than $90 \%$ of the $\mathrm{Cu}$ and $\mathrm{ZnO}$ nanoparticles were in the size range from 140-210 nm and 56-63 nm respectively. These results indicated that better control of the particle size and its polydispersity.

\section{Atomic Force Microscopic Analysis}

Synthesized $\mathrm{Cu}$ and $\mathrm{ZnO}$ nanoparticles were characterized by Atomic Force Microscopy (AFM) for their size and morphology. The topographical 3D images of irregular $\mathrm{Cu}$ and $\mathrm{ZnO}$ nanoparticles synthesized using natural extract of plant origin are shown in figure $14 \mathrm{a}$ and $\mathrm{b}$ respectively. The particle size of the $\mathrm{Cu}$ and $\mathrm{ZnO}$ nanoparticles were found to be 137 $\mathrm{nm}$ and $69 \mathrm{~nm}$ respectively.

\section{Antibacterial activity of green synthesized nanoparticles}

With ever increasing concerns about the use of antibiotics, alternatives to antibiotics are being looked upon. Metallic nanoparticles are being reported to have good antibacterial activity due to their large surface area to volume ratio (Shah et al., 2014). The antibacterial activities of $\mathrm{Cu}$ and $\mathrm{ZnO}$ NPs against the pathogenic organisms studied are shown in figure 15 . It is quite interesting to note that all bacterial species tested in this study showed good sensitivity towards the green synthesized nanoparticles. Zone of inhibition was observed to be more in gram negative bacteria when compared to gram positive bacteria which might be due to the differences in bacterial pathogen's membrane structures (Rastogi and Arunachalam, 2011).

The environment friendly, green synthesis has yielded $\mathrm{Cu}$ and $\mathrm{ZnO}$ NPs which had a definite antibacterial activity. $\mathrm{Cu}$ and $\mathrm{ZnO}$ NPs were found to have a narrow size distribution with Musa ornate flower sheath and Zea mays cob sheath as reducing agents respectively. Alkaline $\mathrm{pH}$ was found to be optimum for the synthesis of the metallic NPs and though there were size variations, the NPs were spherical in shape. It is concluded that basic data has been generated with green synthesized $\mathrm{Cu}$ and $\mathrm{ZnO}$ nanoparticles and further work is planned for evolving an effective nanoparticles based antibacterial for field use.

\section{Acknowledgements}

The authors thank Government of India and Government of Tamil Nadu for funding this work through the National Agricultural Development Programme (RKVY). The 
authors also thank the Director of Reserach, TANUVAS, Dean, Faculty of Basic Sciences, TANUVAS, Dean, Madras Veterinary College and the Professor and Head, Department of Animal Biotechnology, Madras Veterinary College, Chennai, India for the facilities provided.

\section{References}

Albrecht, M. A., C. W. Evans and Raston, C. L. 2006. Green chemistry and the health implications of nanoparticles. Green Chemistry. 8: 417-432.

Chandran, S. P., M. Chaudhary, R. Pasricha, A. Ahmad and Sastry, M. 2006. Synthesis of gold nanotriangles and silver nanoparticles using Aloe vera plant extract. Biotechnology Progress. 22: 577-583.

Eric, C. N., H. Hui, S. Lisa, G. Homer, M. G. Hugo, B. C. John, E. H. George and Steven, L. S. 2011. Biosynthesis of iron and silver nanoparticles at room temperature using aqueous Sorghum bran extracts. Langmuir. 27(1): 264-271.

Forough, M., and Farhad, K. 2010. Biological and Green Synthesis of Silver Nanoparticles. Turkish Journal of Engineering and Environmental Sciences. 34: 281-287.

Gopinath, M., R. Subbaiya, M. M. Selvam and Suresh, D. 2014. Synthesis of copper nanoparticles from Nerium oleander leaf aqueous extract and its antibacterial activity. International Journal of Current Microbiology and Applied Sciences. 3(9): 814-818.

Juhi, S., M. S. Madan, G. Sarika and Abhijeet, S. 2014. Emerging role of fungi in nanoparticle synthesis and their applications. World Journal of Pharmacy and Pharmaceutical Sciences. 3(9): 1586-1613.

Monalisa P., and Nayak, P. L. 2013. Ecofriendly green synthesis of iron nanoparticles from various plants and spices extract. International
Journal of Plant, Animal and Environmental Sciences. 3(1): 68-78.

Rastogi, L., and Arunachalam, J. 2011. Sunlight based irradiation strategy for rapid green synthesis of highly stable silver nanoparticles using aqueous garlic (Allium sativum) extract and their antibacterial potential. Materials Chemistry and Physics. 129: 558-563.

Sangeetha, N., and Kumaraguru, A. K. 2013. Extracellular synthesis of zinc oxide nanoparticle using seaweeds of gulf of Mannar, India. Journal of Nanobiotechnology. 11: 39 .

Shah, R. K., B. Forishmeeta and Nikahat, P. 2015. Synthesis and characterization of $\mathrm{ZnO}$ nanoparticles using leaf extract of Camellia sinesis and evaluation of their antimicrobial efficacy. International Journal of Current Microbiology and Applied Sciences. 4(8): 444-450.

Shahverdi, A. R., A. Fakhimi, H. R. Shahverdi and Minaian, S. 2007. Synthesis and effects of silver nanoparticles on the antibacterial activity of different antibiotics against Staphylococcus aureus and Escherichia coli. Journal of Nanomedicine. 3(2): 168-171.

Shobha, G., M. Vinutha and Ananda, S. 2014. Biological synthesis of copper nanoparticles and its impact - a review. International Journal of Pharmaceutical Science Invention. 3(8): 2838.

Subhankari, I., and Nayak, P.L. 2013. Synthesis of Copper Nanoparticles Using Syzygium aromaticum (Cloves) Aqueous Extract by Using Green Chemistry. World Journal of Nano Science and Technology. 2(1): 14-17.

Varghese, E., and George, M. 2015. Green synthesis of zinc oxide nanoparticles. International Journal of Advanced Research in Science, Engineering and Technology. 4 (1): 307-314.

\section{How to cite this article:}

Saranya, S., A. Eswari, E. Gayathri, S. Eswari and Vijayarani, K. 2017. Green Synthesis of Metallic Nanoparticles using Aqueous Plant Extract and their Antibacterial Activity. Int.J.Curr.Microbiol.App.Sci. 6(6): 1834-1845. doi: https://doi.org/10.20546/ijcmas.2017.606.214 